\title{
PERFORMANCE CHARACTERISTICS OF THE SERIES HYBRID ELECTRIC VEHICLE WITH HYBRID MODE
}

\author{
Ibrahim A. M. Abdel-Halim, M. Z. Elsherif and Mohamed M. Fathy \\ Faculty of Engineering, Benha University, Egypt
}

\begin{abstract}
In this paper, the equations describing the performance of the series hybrid electric vehicle are derived. Performance characteristics for each part in the vehicle system are obtained when the vehicle is operating in hybrid mode in which the drive motor takes its power from main and peaking power sources.

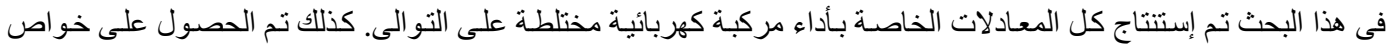

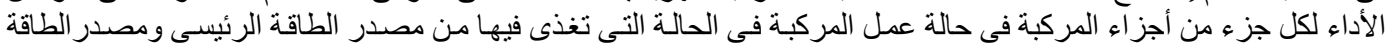

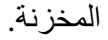

Keywords: Induction motor, electric vehicle, hybrid electric vehicle, hybrid mode.

\section{INTRODUCTION}

Hybrid electric vehicles (HEVs) contain two energy sources to propel the vehicle. One of these energy sources is mechanical, which is an internal combustion engine (ICE), and the other is an energy storage device or a peaking power supply which may be either an electrochemical battery, super capacitors or electromechanical flywheel battery [1-3].

Thus, the hybrid electric vehicle is a hybrid between the conventional vehicle, ICE vehicle, and the pure electric vehicle $(\mathrm{EV})$, so that it can take merits and overcome problems concerned with these two types of vehicles.

According to the orientation of the two energy sources in the propulsion system, there are two common configurations of hybrid electric vehicles; which are the series and parallel configurations [1-4].

The series HEVs only have an electric propulsion system coupled to the wheels and there is no mechanical connection between the internal combustion and the wheels axle however in the parallel hybrid electric vehicle configuration, both the internal combustion engine and the electric motor are mechanically coupled to the drive wheels.

In series HEVs the power for the electric propulsion system comes from the peaking power source and/or an electric generator, which is coupled to the internal combustion engine. The internal combustion engine and the generator are normally used for highway driving while the peaking power source provides added power during acceleration, hill climbing and other periods of high power demand [3]. This mode of operation, in which both power sources are used to feed the drive motor, is the hybrid mode of operation.

In this paper it will be assumed that the peaking power source used is a bank of electrochemical batteries and the performance of the series $\mathrm{HEV}$ in the hybrid mode is investigated. The system of the series HEV investigated is shown in Fig.1. This system consists of four main subsystems; which are the main power supply subsystem, the peaking power supply subsystem, the vehicle speed subsystem and the DC bus subsystem.

\section{PERFORMANCE EQUATIONS OF THE SERIES HEV WITH HYBRID MODE}

This mode of operation of the series HEV may be used when a large amount of power is demanded, such as during sharp acceleration or steep hill climbing. In this mode the electric motor drive takes its power from both the main and peaking power sources.

To investigate the series $\mathrm{HEV}$ performance at acceleration it will be assumed that the vehicle is accelerated with the drive motor is fed from a variable-voltage, variable-frequency source; with its air-gap flux is kept constant at the value corresponding to fundamental frequency.

The tractive force developed at the shaft of the wheel axle during acceleration can be expressed by: 


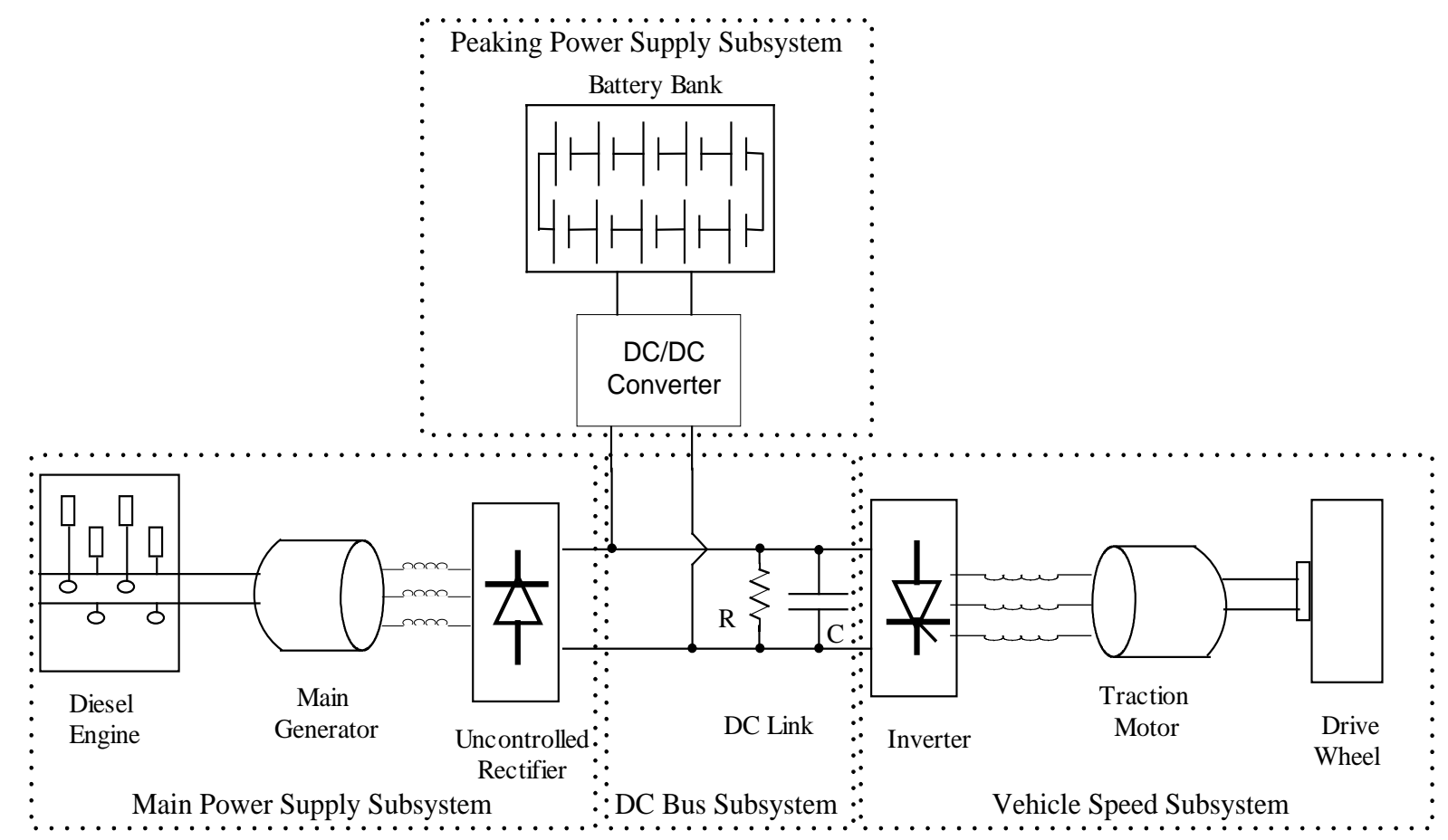

Fig.1 The Series HEV System

$$
\mathrm{F}_{\mathrm{TR}}=\mathrm{k}_{\mathrm{m}} \mathrm{M}_{\mathrm{veh}} \frac{\mathrm{dV}_{\mathrm{veh}}}{\mathrm{dt}}+\mathrm{F}_{\mathrm{RL}}
$$

where FRL $=$ C0 Mveh $g+0.5 \rho$ CD Af Vveh2 Therefore the acceleration of the vehicle can be expressed by:

$$
\frac{\mathrm{dV}_{\mathrm{veh}}}{\mathrm{dt}}=\frac{1}{\mathrm{k}_{\mathrm{m}} \mathrm{M}_{\mathrm{veh}}}\left(\mathrm{F}_{\mathrm{TR}}-\mathrm{F}_{\mathrm{RL}}\right)
$$

Thus, the torque at the shaft of the wheel axle can be expressed by:

$$
\mathrm{T}_{\mathrm{wh}}=\left[\mathrm{C}_{0} \mathrm{M}_{\mathrm{veh}} \mathrm{g}+0.5 \rho \mathrm{C}_{\mathrm{D}} \mathrm{A}_{\mathrm{f}} \mathrm{V}_{\mathrm{veh}}{ }^{2}\right] \mathrm{r}_{\mathrm{wh}}+\mathrm{T}_{\mathrm{b}}
$$

The developed power at the shaft of the wheel axle can be determined by;

$$
\mathrm{P}_{\mathrm{wh}}=\mathrm{T}_{\mathrm{wh}} \mathrm{V}_{\mathrm{veh}} / \mathrm{r}_{\mathrm{wh}}
$$

The motor speed can be expressed in terms of the vehicle speed as:

$\omega_{\mathrm{m}}=\mathrm{m} \frac{\mathrm{V}_{\mathrm{veh}}}{\mathrm{r}_{\mathrm{wh}}}$

where $\mathrm{m}$ is the gear ratio of the mechanical coupling between the induction motor and the axle of the vehicle wheels.
Therefore, the motor torque is expressed by:

$$
\mathrm{T}_{\mathrm{im}}=\frac{\mathrm{P}_{\mathrm{wh}}}{\eta_{\mathrm{tmw}} \omega_{\mathrm{m}}}
$$

or by

$$
\mathrm{T}_{\mathrm{im}}=\frac{\mathrm{T}_{\mathrm{wh}}}{\eta_{\mathrm{tmw}} \omega_{\mathrm{m}}} \frac{\mathrm{V}_{\mathrm{veh}}}{\mathrm{r}_{\mathrm{wh}}}
$$

where $\eta t m w$ is the efficiency of the transmission between the traction motor and the wheel axle. The corresponding tractive force will, thus, be:

$$
\mathrm{F}_{\mathrm{TR}}=\frac{\mathrm{T}_{\mathrm{im}} \eta_{\mathrm{tmw}} \omega_{\mathrm{m}}}{\mathrm{V}_{\mathrm{veh}}}
$$

Substituting from eqn.(5) into eqn.(6), the motor torque can be expressed in terms of the vehicle speed as:

$$
\mathrm{T}_{\mathrm{im}}=\frac{\mathrm{P}_{\mathrm{wh}} \mathrm{r}_{\mathrm{wh}}}{\eta_{\mathrm{tmw}} \mathrm{mV}_{\text {veh }}}
$$

The DC bus power can be expressed by:

$\mathrm{P}_{\text {bus }}=\frac{\mathrm{P}_{\mathrm{m} \_ \text {in }}}{\eta_{\mathrm{mc}}}$

where $\eta_{\mathrm{mc}}$ is the efficiency of the converter. 
At standstill $\left(\omega_{\mathrm{m}}=0\right)$ the motor developed torque can be determined in terms of the torque at the shaft of the wheel axle by the relationship:

$\mathrm{T}_{\text {whst }}=\mathrm{m} \mathrm{T}_{\text {imst }}$

The corresponding tractive force will thus be:

$\mathrm{F}_{\mathrm{TRst}}=\frac{\mathrm{T}_{\mathrm{whst}}}{\mathrm{r}_{\mathrm{wh}}}$

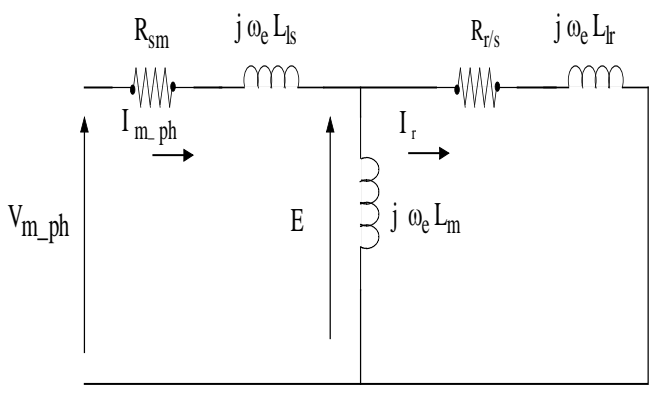

Fig.2 Equivalent circuit of the induction motor

\section{PRINCIPLE OF NUMERICAL SOLUTION}

Starting from zero vehicle speed, the motor speed would be equal to zero. Then using the motor equivalent circuit shown in Fig.2 at known voltage and frequency, the developed torque of the induction motor at standstill, $\mathrm{T}_{\text {imst }}$, can be obtained. The corresponding tractive force, $F_{\text {TRst }}$, can, thus, be obtained from eqn.(12).

Using this value of tractive force into eqn.(2), the next vehicle speed can be obtained by integrating this equation numerically over an appropriate time step. For the second and following time steps of numerical solution, the corresponding motor speed is obtained from eqn.(5) and the motor equivalent circuit is used to obtain its developed torque and the corresponding tractive force is obtained from eqn.(8). This process continues until the vehicle reaches steady-state speed.

\section{SIMULATION RESULTS}

The approach presented in (3), was applied using $4^{\text {th }}$ order Runge-Kutta numerical method of integration with the air-gap flux of the motor kept constant. Several performance characteristics of the vehicle during acceleration, at different voltage and frequency of the motor using the data of the induction motor and vehicle given in Appendix (A) are obtained:

Fig.3 shows the variation of the vehicle speed throughout the acceleration period. From this figure it is clear that the vehicle reaches a higher final steady-state speed as the motor voltage and frequency increases.

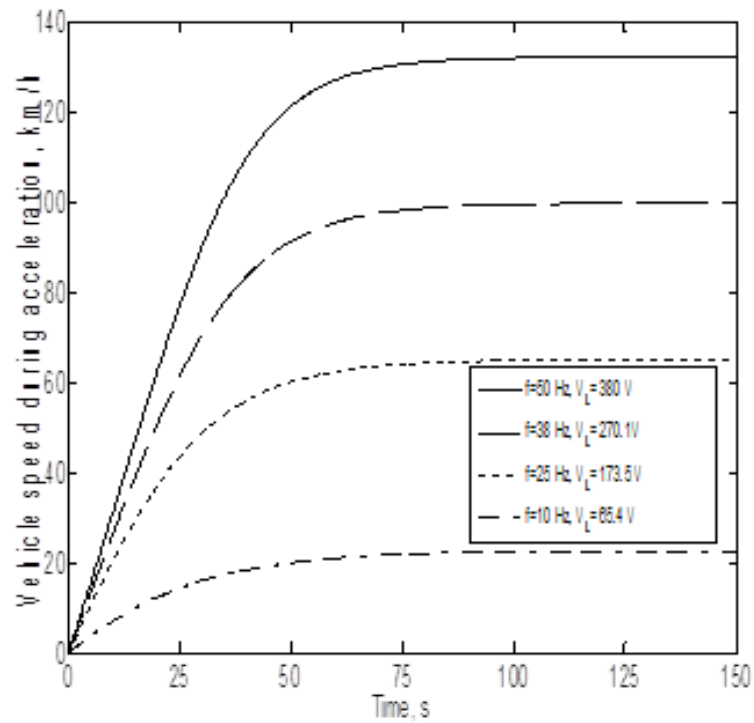

Fig.3 Vehicle speed versus time during acceleration

The tractive and resisting forces, $\mathrm{F}_{\mathrm{TR}}$ and $\mathrm{F}_{\mathrm{RL}}$ respectively, are plotted against time during acceleration and until steady-state conditions are reached, at the same values of the voltage and frequency used to obtain Fig.3, as shown in Figs.4-7. From these figures it is clear that, as the voltage and frequency increase the vehicle will take a shorter time to accelerate to steady-state speed at which $\mathrm{F}_{\mathrm{TR}}$ equal $\mathrm{F}_{\mathrm{RL}}$.

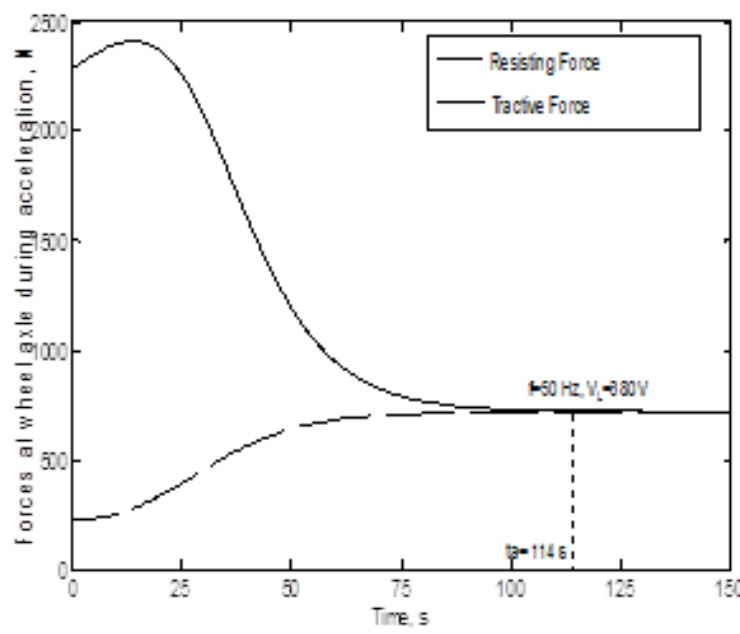

Fig. 4 Tractive and resisting forces at wheel axle versus time $(\mathrm{f}=50 \mathrm{~Hz}, \mathrm{VL}=380 \mathrm{~V})$ 


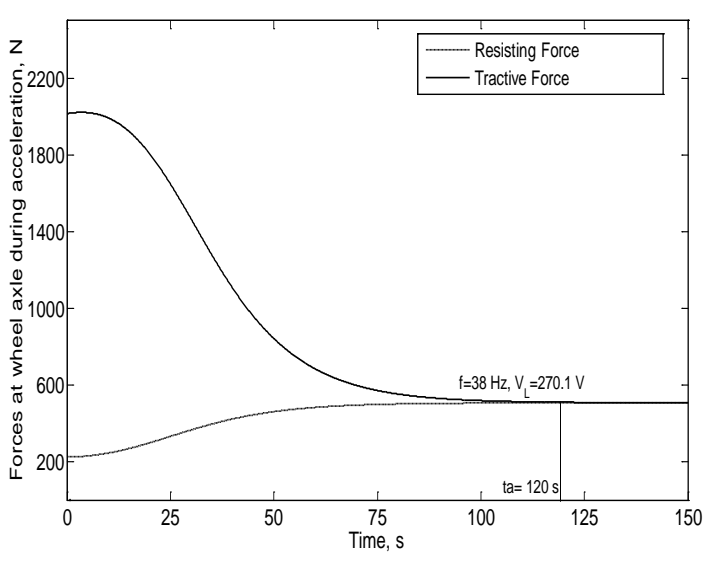

Fig.5 Tractive and resisting forces at wheel axle versus time $(\mathrm{f}=38 \mathrm{~Hz}, \mathrm{VL}=270.1 \mathrm{~V})$

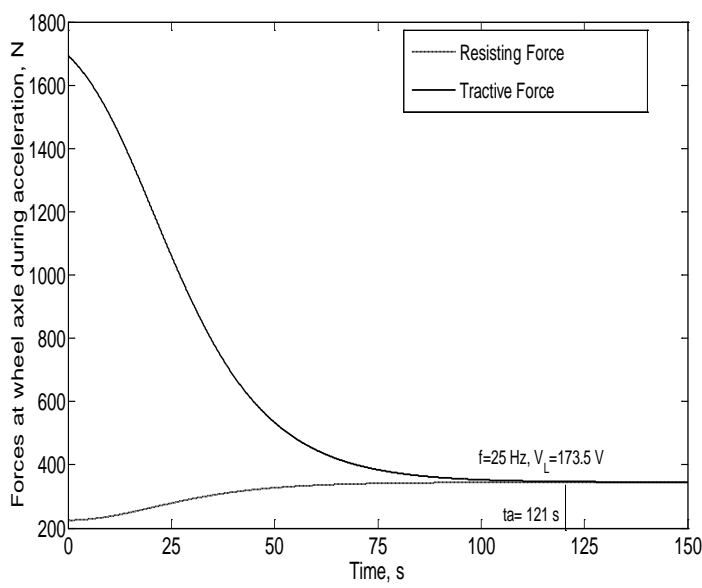

Fig.6 Tractive and resisting forces at wheel axle versus time $(\mathrm{f}=25 \mathrm{~Hz}, \mathrm{VL}=173.5 \mathrm{~V})$

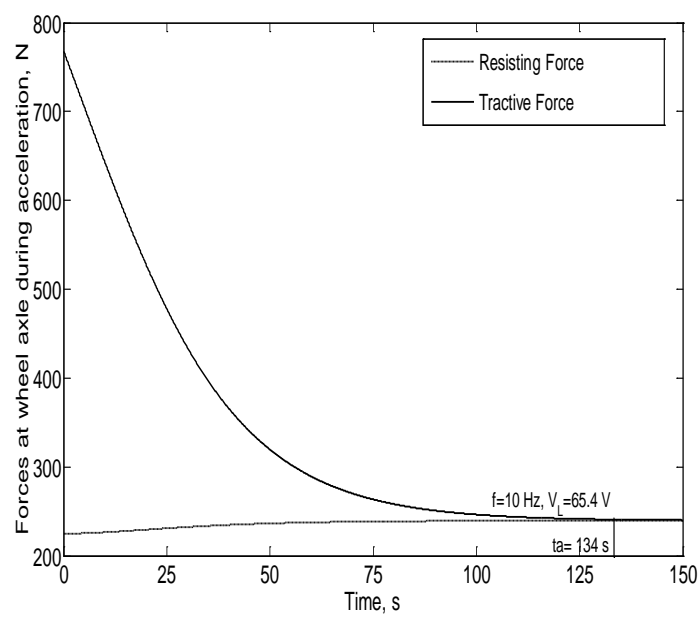

Fig.7 Tractive and resisting forces at wheel axle versus time $(\mathrm{f}=10 \mathrm{~Hz}, \mathrm{VL}=65.4 \mathrm{~V})$
The tractive and resisting forces, FTR and FRL, can also be drawn against the vehicle speed during the acceleration period until steady-state conditions are reached, for different values of motor voltage and frequency, as shown in Figs.8-11. From these figures it is clear that, for certain voltage and frequency values, the tractive force decreases and the resisting force increases as the vehicle speed increases up to steady-state speed at which the tractive and resisting forces are equal. For a certain vehicle speed, the tractive force decreases while the resisting force is constant for the several values of voltage and frequency used when their values decrease.

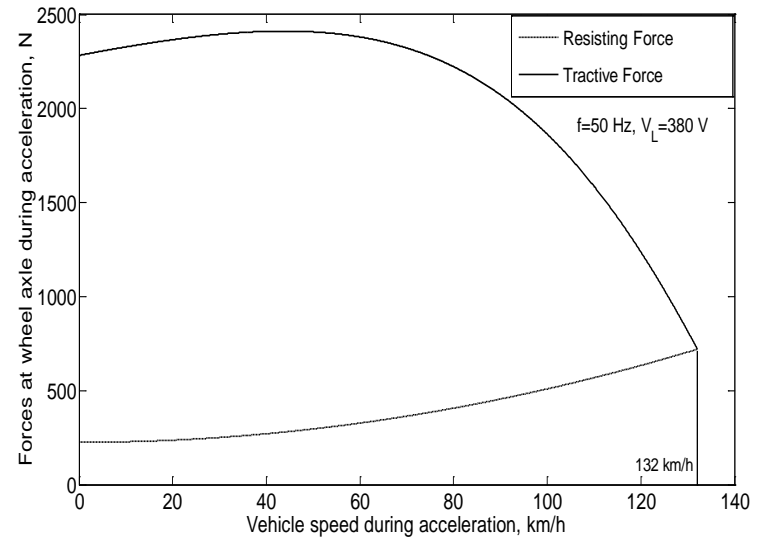

Fig.8 Tractive and resisting forces at wheel axle versus vehicle speed during acceleration $(\mathrm{f}=50 \mathrm{~Hz}$, $\mathrm{VL}=380 \mathrm{~V}$ )

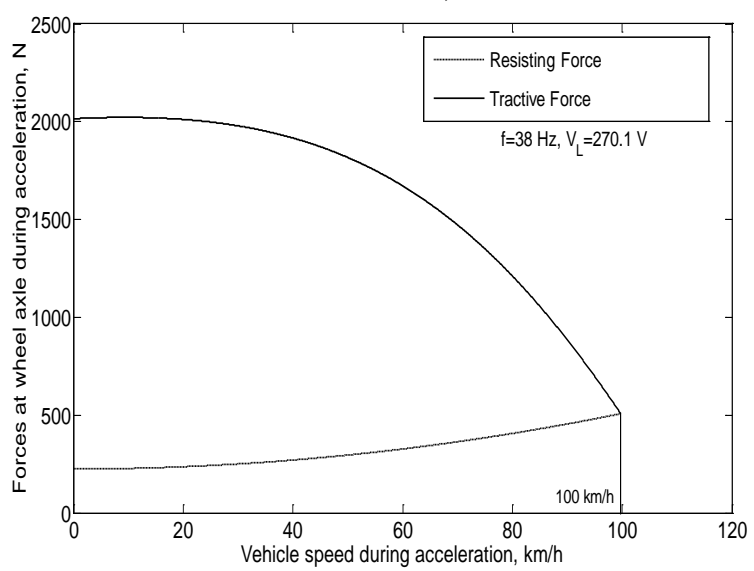

Fig.9 Tractive and resisting forces at wheel axle versus vehicle speed during acceleration $(\mathrm{f}=38 \mathrm{~Hz}$, $\mathrm{VL}=270.1 \mathrm{~V}$ )

Using the values of the vehicle speed, which are obtained at different values of motor voltage and frequency, into eqn.(3), the characterisitics of the torque at the wheel axle, Twh, can be drawn versus the vehicle speed, during acceleration until steadystate conditions are reached, as shown in Fig.12. From this figure it is noticed that the torque applied on the wheel axle has the same shape as that of the corresponding tractive force shown in Fig. 8 to Fig. 11 and for the same vehicle speed the torque decreases as the used values of the voltage and frequency decrease. 


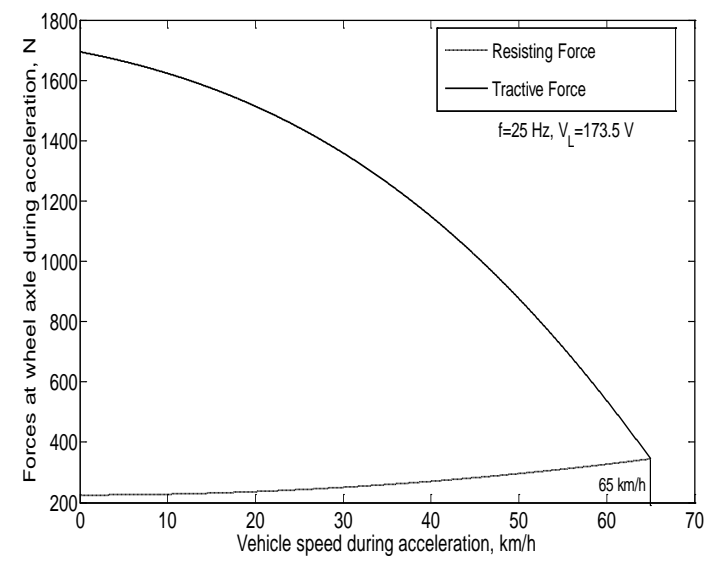

Fig.10 Tractive and resisting forces at wheel axle versus vehicle speed during acceleration $(\mathrm{f}=25 \mathrm{~Hz}$, $\mathrm{VL}=173.5 \mathrm{~V}$ )

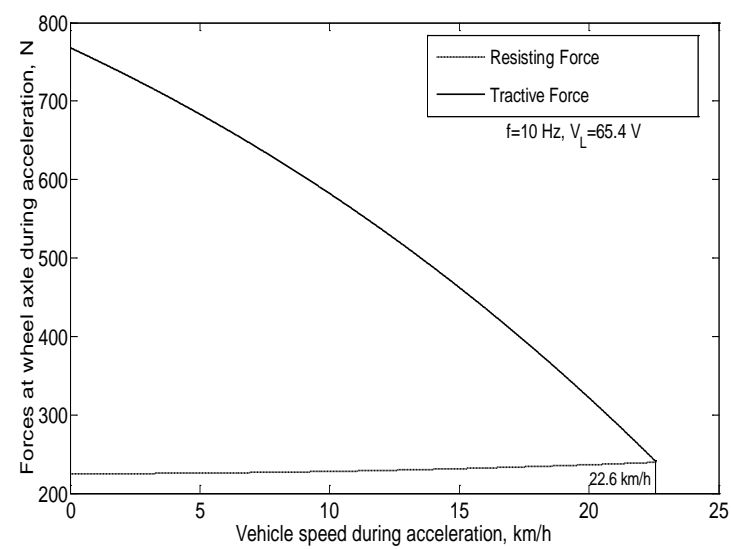

Fig.11 Tractive and resisting forces at wheel axle versus vehicle speed during acceleration $(\mathrm{f}=10 \mathrm{~Hz}$, $\mathrm{VL}=65.4 \mathrm{~V}$ )

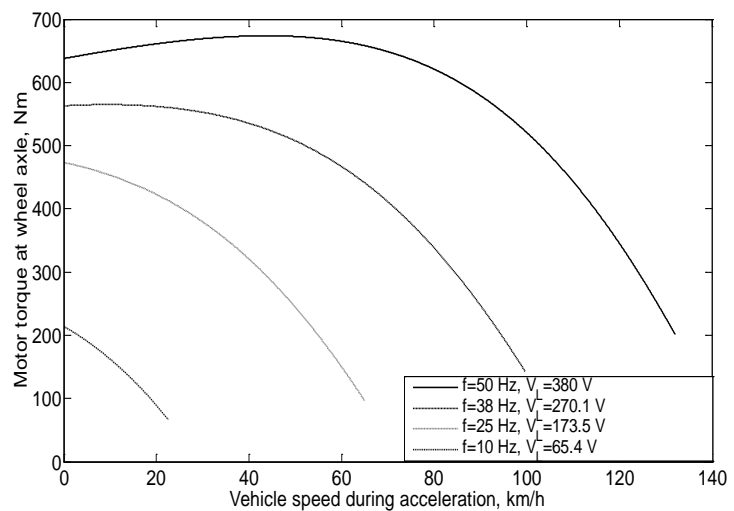

Fig.12 Torque applied on wheel axle versus vehicle speed

From Eqn. (4) the characteristics of the developed power at the wheel axle, can be obtained against time and against the vehicle speed, at different values of the motor voltage and frequency, as shown in Figs.13 and 14 respectively.

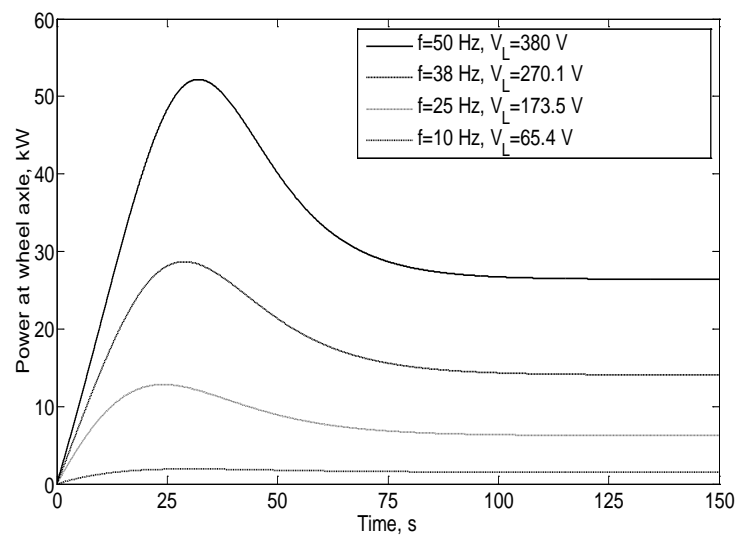

Fig.13 Developed power at wheel axle versus time

From Fig.13 it is clear that at certain values of voltage and frequency, the developed power at the wheel axle increases until it reaches a maximum value and then decreases as the time increases until the vehicle reaches steady-state speed at which the developed power becomes constant. Also, at any instant of time the developed power has higher values at higher voltages and frequencies.

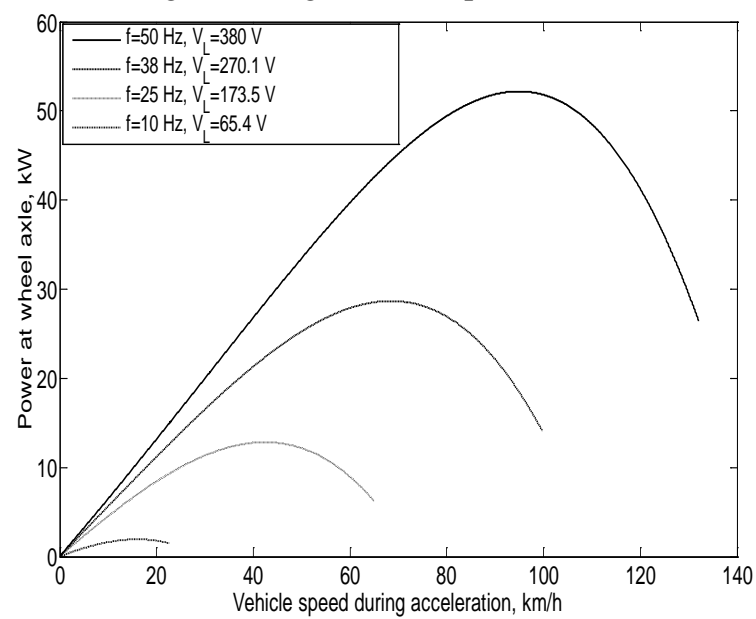

Fig.14 Developed power at wheel axle versus vehicle speed

From Fig.14 for certain values of motor voltage and frequency, the developed power at the wheel axle increases to a maximum value and then decreases as the vehicle speed increases. Also, at certain vehicle speed the developed power has higher values at higher voltages and frequencies, and the vehicle speed, at which the developed power on the wheel axle will have a maximum value, is increasing as the motor voltage and frequency increases.

From Eqn. (9) the motor torque can be calculated at different values of the vehicle speed. Then using these values of the motor torque into the motor equivalent circuit shown in Fig.2, the motor input current can be determined and plotted against time and against vehicle speed, for different values of voltages and frequencies, as shown in Figs.15 and 16 respectively. 


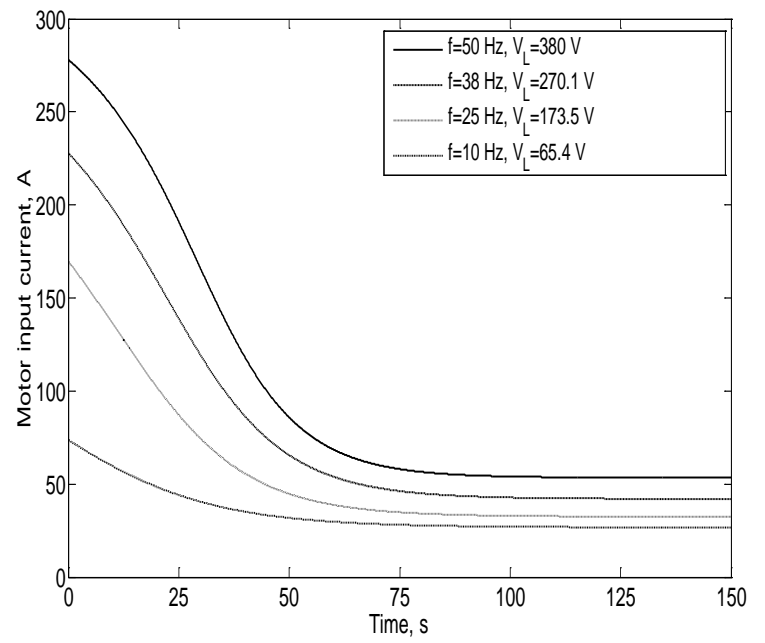

Fig.15 Motor input current versus time

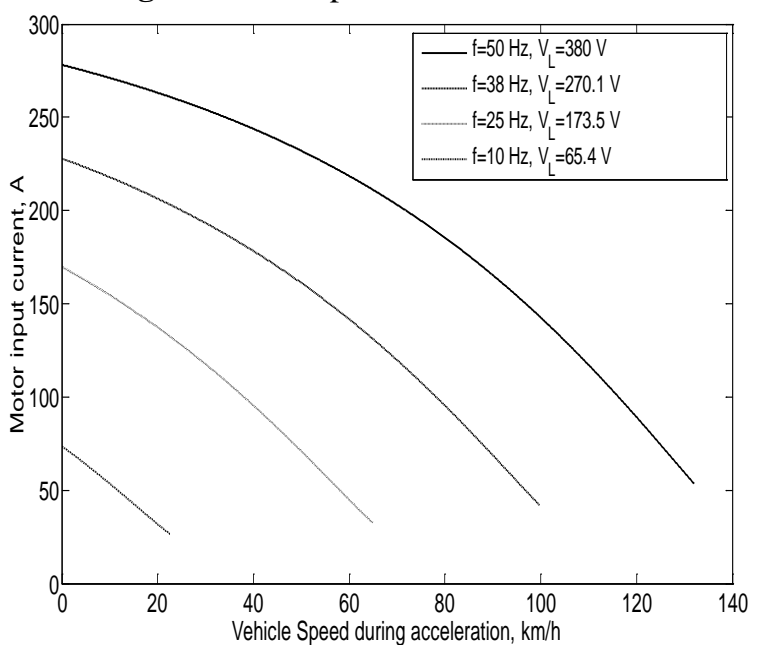

Fig.16 Motor input current versus vehicle speed during acceleration

From Figs.15 and 16 it is clear that at certain values of voltage and frequency, the motor input current decreases as the vehicle accelerates and reaches a constant rms value at steady state. For any time instant, Fig.15, or vehicle speed, Fig.16, the motor input current will have larger values for higher values of voltage and frequency.

Determining the motor input current and power factor at different values of the motor voltage and frequency, the motor input power, Pm_in, can be also computed.

Using the different values of the computed motor input power, at different values of the motor voltage and frequency, into eqn.(10) the DC bus power can be obtained during the acceleration period as shown in Figs. 17 and 18 respectively.

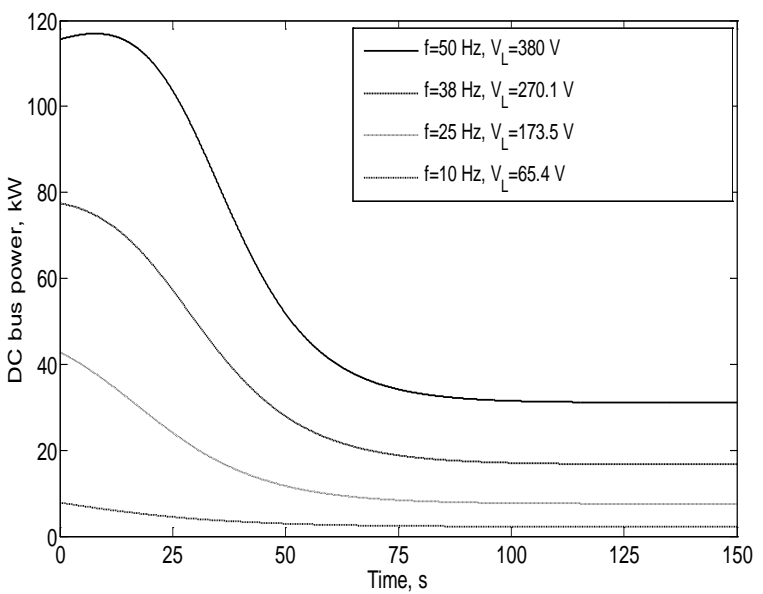

Fig.17 DC bus power versus time during acceleration

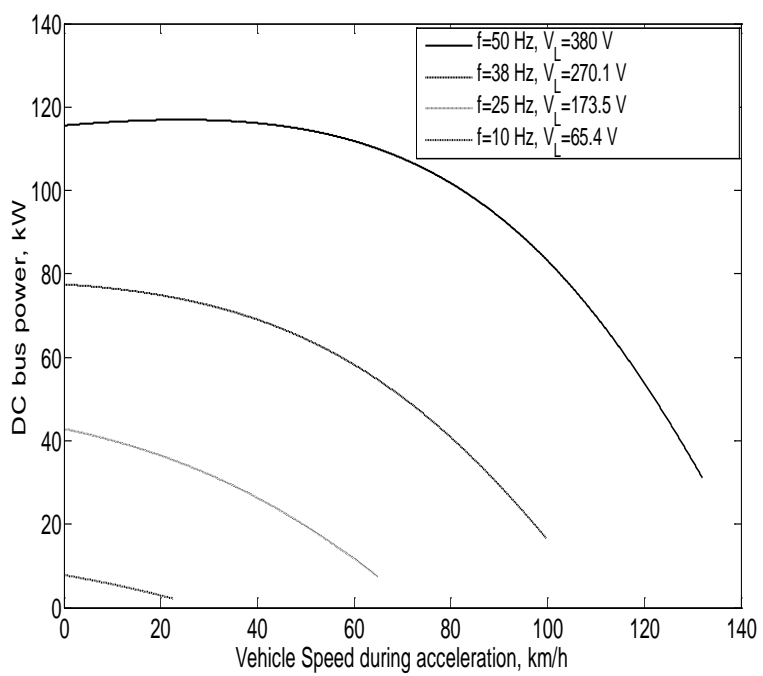

Fig.18 DC bus power versus vehicle speed during acceleration

From these figures it is clear that the DC bus power characteristics are similar in shape to the motor input current characteristics which means that at a constant voltage and frequency, the DC bus power decreases as the vehicle accelerates and then at a constant vehicle speed the DC bus power decreases as the voltage and frequency decreases.

\section{CONCLUSIONS}

From the performance characteristics of the series HEV operating in the hybrid mode, the following is observed, as the motor voltage and frequency increases:

- The vehicle reaches a higher final steady-state speed.

- The vehicle will take a shorter time to accelerate to steady-state speed.

- The tractive force increases while the resisting force is constant for a certain vehicle speed.

- The motor torque increases for a certain vehicle speed.

- The developed power has higher values at certain vehicle speed or at any instant of time. 
- The motor input current will have larger values for any time instant or vehicle speed.

- The DC bus power increases at a constant vehicle speed.

Also for certain operating values of the motor voltage and frequency:

- The tractive force decreases and the resisting force increases as the vehicle speed increases up to steady-state speed at which the tractive and resisting forces are equal.

- The developed power at the wheel axle increases until it reaches a maximum value and then decreases as the time increases until the vehicle reaches steady-state speed at which the developed power becomes constant.

- The motor input current decreases as the vehicle accelerates and reaches a constant rms value at steady state.

- The DC bus power decreases as the vehicle accelerates.

\section{List of symbols}

\begin{tabular}{|l|l|}
\hline Af & $\begin{array}{l}\text { Equivalent frontal area of the vehicle in } \\
\text { m2. }\end{array}$ \\
\hline C0 & Coefficient of rolling resistance. \\
\hline CD & Aerodynamic drag coefficient. \\
\hline FRL & Road load force in N. \\
\hline FTR & Tractive force in N. \\
\hline g & $\begin{array}{l}\text { Gravitational acceleration constant in } \\
\text { m/s2. }\end{array}$ \\
\hline km & Rotational inertia coefficient. \\
\hline m & Gear ratio of the gear box \\
\hline Mveh & Total mass of the vehicle in kg. \\
\hline Pbus & Input DC bus power in W. \\
\hline Pwh & $\begin{array}{l}\text { Power at at the shaft of the wheel axle } \\
\text { in W. }\end{array}$ \\
\hline Pm-in & $\begin{array}{l}\text { Input power of the induction motor in } \\
\text { W. }\end{array}$ \\
\hline rwh & Radius of the wheel in m. \\
\hline Tb & Frictional brake torque in Nm. \\
\hline Tim & $\begin{array}{l}\text { Developed torque of the induction } \\
\text { motor in Nm. }\end{array}$ \\
\hline Twh & $\begin{array}{l}\text { Load torque at the shaft of the wheel } \\
\text { axle in Nm. }\end{array}$ \\
\hline Vveh & Vehicle speed in km/h. \\
\hline$\gamma$ & Grade angle. \\
\hline$\eta m c$ & Efficiency of the motor converter. \\
\hline$\eta t m w$ & $\begin{array}{l}\text { Efficiency of transmission between the } \\
\text { traction motor and the wheel axle. }\end{array}$ \\
\hline$\rho$ & Air density in kg/m3. \\
\hline$\omega m$ & Motor speed in rad/s. \\
\hline
\end{tabular}

\section{Appendix (A)}

Data of the induction motor

Pmr $=41.3 \mathrm{~kW}, \mathrm{Vmr}=380 \mathrm{~V}$, fr $=50 \mathrm{~Hz}$, star connected 3-phase induction motor, $\mathrm{nr}=1230 \mathrm{rpm}$, $\mathrm{sr}=0.18, \mathrm{P}=4$ poles, $\eta \mathrm{m}=0.85$, $\mathrm{Rsm}=0.0862 \mathrm{ohm}$, $\mathrm{Rr}=0.427 \mathrm{ohm}, \quad \mathrm{Lm}=0.029974 \mathrm{H}$, Lls $=$ Llr $=9.761503 \times 10-4 \mathrm{H}$.

\section{Vehicle dynamic parameters}

$\rho=1.225 \mathrm{~kg} / \mathrm{m} 3, \mathrm{CD}=0.3$, Af $=2 \mathrm{~m} 2$, Mveh $=2250$ $\mathrm{kg}$, rwh $=0.2794 \mathrm{~m}, \mathrm{~Tb}=0$, Vveh-max $=120 \mathrm{~km} / \mathrm{h}, \mathrm{Vf}$ $=100 \mathrm{~km} / \mathrm{h}, \mathrm{km}=1.08, \mathrm{C} 0=0.01, \mathrm{~g}=9.81 \mathrm{~m} / \mathrm{s} 2$, $\mathrm{m}=1.1, \eta \mathrm{mc}=0.98$, $\eta \mathrm{tmw}=0.95$, Rbus $=510$.

\section{REFERENCES}

[1] D.Assanis, G. Delagrammatikas, R. Fellini, Z. Filipi, J. Liedtke, N. Michelena, P. Papalambros, D. Reyes, D. Rosenbaum, A. Sales and M. Sasena: An optimization approach to hybrid electric propulsion system design. Mechanics of Structures and Machines, Vol. 27, No. 4, 1999, pp. 393-421.

[2] Matthew Alan Merkle: Variable bus voltage modeling for series hybrid electric vehicle simulation. Master Thesis, Virginia Polytechnic Institute and State University, December 1, 1997 Blacksburg, Virginia.

[3] Tom Ciccarelli and Reza Toossi: Assessment of Hybrid Configuration and Control Strategies in Planning Future Metropolitan/Urban Transit Systems. Final Report, California state university, May 20, 2002, pp. 1-63.

[4] Jay A. Farrell, Matthew J. Barth, and James W. Heffel: Hydrogen-Powered Advanced HybridElectric Vehicles. Final Report, College of Engineering-Center for Environmental Research and Technology University of California, August 31, 1998, pp. 1-101, Riverside.

[5] Mehrdad Ehsani, Yimin Gao, Sebastien E. Gay and Ali Emadi: Modern Electric, Hybrid Electric, and Fuel Cell Vehicles Fundamentals, Theory, and Design. CRC Press LLC, 2005. 